\title{
Stochastic modelling of fatigue crack growth
}

\author{
Abayomi Omishore \\ Department of Structural Mechanics, Faculty of Civil Engineering, \\ University of Technology, Brno, Czech Republic
}

E-mail:omishore.a@fce.vutbr.cz

\begin{abstract}
The article deals with the influence of the skewness of quasi-constant stress range on the fatigue resistance of a steel bridge member subjected to multiple repeated loading. It is shown that it is necessary to know the statistical characteristics and type of probability density function relatively accurately in the case of quasi-constant stress range, otherwise the estimation of the fatigue resistance may be inaccurate. The fatigue resistance is studied using linear fracture mechanics. The random characteristics of the steel member are simulated using the Latin Hypercube Sampling method. The results of experimental research on calibration functions used in linear fracture mechanics are applied in this study. The calibration function for pure bending, which is presented on an extended domain of relative crack length, is applied. Non-parametric rank-order correlation identifies a strong influence of the quasi-constant stress range on the fatigue resistance. A detailed comparison of three variants of fatigue resistance as output random variables is performed. The results show that the probabilistic assessment of reliability may be burdened with greater or lesser epistemic uncertainty, which can distort the estimates of the remaining service life of the load bearing bridge member.
\end{abstract}

Keywords: fatigue, resistance, steel, correlation, crack.

\section{Introduction}

Steel bridges are exposed to degradation processes, which can reduce their service life very rapidly. Stress history is one of the many factors influencing the expected service life of steel bridges in the Czech Republic. Other factors are material characteristics and the environment, which exhibit uncertainty and randomness during the service life of the bridge. The nature of fatigue processes and uncertainties associated with traffic intensity and the estimation of future loads requires field inspections as a necessary tool for fatigue damage detection and prevention. In view of these facts, it is more appropriate to conduct fatigue life assessment in a probabilistic way rather than using deterministic procedures. A general overview of research development in the field of fatigue life assessment of steel bridges performed using literature with theory pertaining to fatigue, methods, technology and application has been published in (e.g. Ye, Su, \& Han, 2014).

Fatigue analysis has been developed to provide designers and engineers with methods that practically, easily and cost-effectively assess the service life of load bearing structures (e.g. Cui, 2002; Zerbst et al., 2016). Propagation of fatigue cracks occurs due to stress changes, which can be analysed using the finite element method. The analysis of reliability and limit states of load bearing structural members and geotechnical bodies is usually based on advanced statistical methods (e.g. Kala, 2012; Kala \& Valeš, 2017; Kala, Valeš, \& Jönsson, 2017; Jönsson, Müller, Gamst, Valeš, \& Kala, 2019; Chalmovský et al., 2017) and sensitivity analysis (Kala \& Valeš, 2018; Štefaňák, Kala, Miča, \& Norkus, 2018). Stochastic modelling of fatigue processes is preceded by experimental research (Seitl, Miarka, Malíková, \& Krejsa, 2017). Probabilistic methods along with linear fracture mechanics (Kala, 2008; Krejsa, Kala, \& Seitl, 2016) and experimentally obtained data (Seitl et al., 2017) provide a widely usable platform for the analysis of basic and higher statistical characteristics of fatigue resistance. The outputs of stochastic models provide information for decision-making methods, which results in the optimal selection of a procedure among several alternative options (Antucheviciene, Kala, Marzouk, \& Vaidogas, 2015). Decision-making methods are usually based on probabilistic and sensitivity analysis methods, but more often use fuzzy and alternative procedures that process tacit knowledge, thereby filling the gaps in finding satisfactory solutions in complex decision-making processes (Ghorabaee, Amiri, Zavadskas, \& Antucheviciene, 2018).

Fatigue load and resistance are two main variables considered when the stress-life method is selected for the development of fatigue reliability analytical models. A substantial number of studies on the assessment of fatigue 
reliability of bridges have been performed using the approach of fracture mechanics (Guo \& Chen, 2013). The presented article presents some methodological issues that need to be addressed in the stochastic analysis of fatigue resistance.

\section{Fatigue resistance based on fracture mechanics and experimental research}

Crack growth is dependent on the number of load fatigue cycles $N$. Linear elastic fracture mechanics is used to study the propagation of crack length $a$ from initial size $a_{0}$ to the critical size $a_{c r}$, upon which fatigue fracture occurs. Paris-Erdogan law relates the stress intensity factor range to the sub-critical crack growth under a fatigue stress regime (Paris \& Erdogan, 1963).

$$
\frac{d a}{d N}=C \cdot \Delta K^{m}
$$

where $\mathrm{d} a / \mathrm{d} N$ is the crack growth rate denoting the crack growth for a load cycle, $m$ and $C$ are Paris-Erdogan law constants that depend on the material, environment and stress ratio, and $\Delta K$ is the range of the stress intensity factor during the fatigue cycle. Figure 1 shows a schematic plot of the typical relationship between the crack growth rate and $\Delta K$. In practice, the Paris law is calibrated to model the linear interval around the centre, see Figure 1.

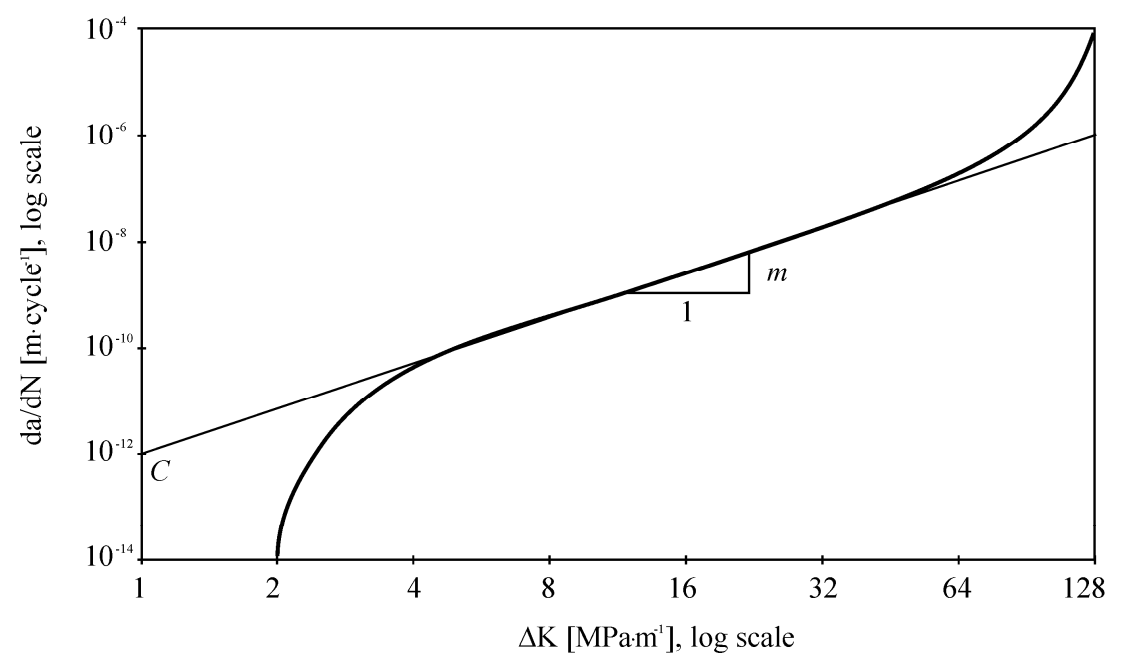

Figure 1. Dependence between crack growth rate and range of the stress intensity factor

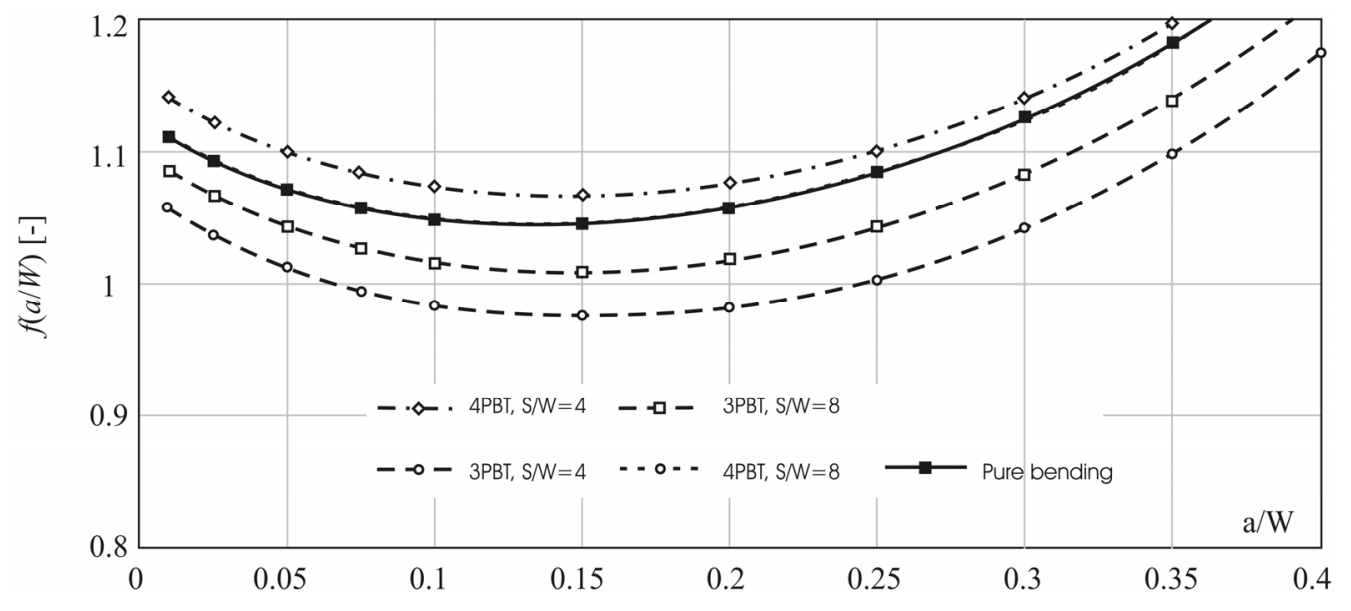

Figure 2. Experimentally obtained calibration functions (Seitl et al., 2017, 2018)

The stress intensity factor range $\Delta K$ during the fatigue cycle can be determined as:

$$
\Delta K=\sqrt{\pi a} \cdot \Delta \sigma \cdot f\left(\frac{a}{W}\right),
$$

where $a$ is the length of the crack, $W$ is the width of the specimen, $\Delta \sigma$ is the quasi-constant stress range and $f(a / W)$ is the calibration function derived from experimental research published in (Seitl et al., 2017, 2018), see Figure 2. 
The fatigue resistance based on linear fracture mechanics can be defined as the number of loading cycles for the propagation of the crack from size $a_{0}$ to the critical size $a_{c r}$. The pure bending load action of the corresponding curve on Figure 2 are used. The value of fatigue resistance $N_{F}$ (Omishore, 2018) can be derived by integrating Paris's law and substituting $\log (C)=-11.141+-0.507 \cdot m$ as:

$$
N_{F}=\frac{1}{e^{(-11.141-0.507 \cdot m)} \cdot \Delta \sigma^{m}} \cdot \int_{a_{0}}^{a_{c r}} \frac{1}{[f(a / W) \cdot \sqrt{\pi \cdot a}]^{m}} d a .
$$

\section{Input random quantities}

The study is aimed at the stochastic analysis of fatigue resistance $N_{F}$, which is calculated using linear fracture mechanics according to Eq. (3). A more detailed procedure for calculating $N_{F}$ can be found in (e.g. Omishore, 2018). The input random variables of the probabilistic model are listed in Table 1. The coefficients of variation of input variables are approximately the same as those listed in (Kala, 2008; Omishore, 2018). The initial crack size $a_{0}$ is introduced using a generally suitable and widely implemented lognormal probability density function (pdf) (Kala, 2008; Omishore, 2018). Gauss pdf is considered for the other random variables with the exception of $\Delta \sigma$. The stress range $\Delta \sigma$ is introduced with Gauss and Hermite pdfs, which are available in the software Statrel 3.10, see Figure 3.

Table 1. Input random quantities

\begin{tabular}{|l|c|c|c|c|c|c|c|}
\hline \multicolumn{1}{|c|}{ Description } & Symbol & Pdf & Unit & Mean value & Std. deviation & Skewness & Kurtosis \\
\hline Initial crack length & $a_{0}$ & log-normal & $\mathrm{mm}$ & 0.526 & 0.504 & 3.73 & 33.75 \\
\hline Critical crack & $a_{c r}$ & Gauss & $\mathrm{mm}$ & 100 & 8 & 0 & 3 \\
\hline Specimen width & $W$ & Gauss & $\mathrm{mm}$ & 230 & 12 & 0 & 3 \\
\hline Paris exponent & $m$ & Gauss & - & 3 & 0.03 & 0 & 3 \\
\hline Stress range - variant 1 & $\Delta \sigma_{\mathrm{v} 1}$ & Hermite & $\mathrm{MPa}$ & 60 & 10 & 0.5 & 3 \\
\hline Stress range - variant 2 & $\Delta \sigma_{\mathrm{v} 2}$ & Gauss & $\mathrm{MPa}$ & 60 & 10 & 0 & 3 \\
\hline Stress range - variant 3 & $\Delta \sigma_{\mathrm{v} 3}$ & Hermite & $\mathrm{MPa}$ & 60 & 10 & -0.5 & 3 \\
\hline
\end{tabular}

The aim of the study is to investigate the influence of skewness of quasi-constant stress range $\Delta \sigma$ on the fatigue resistance $N_{F}$. The skewness and kurtosis are higher statistical moments by which the realistically measured observations deviate from the Gauss pdf. The approximate neglect of skewness and kurtosis and the consideration of Gauss pdf is acceptable provided that the effects of skewness and kurtosis on the output variable are small. Otherwise, higher statistical moments should be taken into account. Statistical analysis is performed with ten thousand samples using the Latin Hypercube Sampling (LHS) method (McKey, Beckman, \& Conover, 1979; Iman \& Conover, 1980).

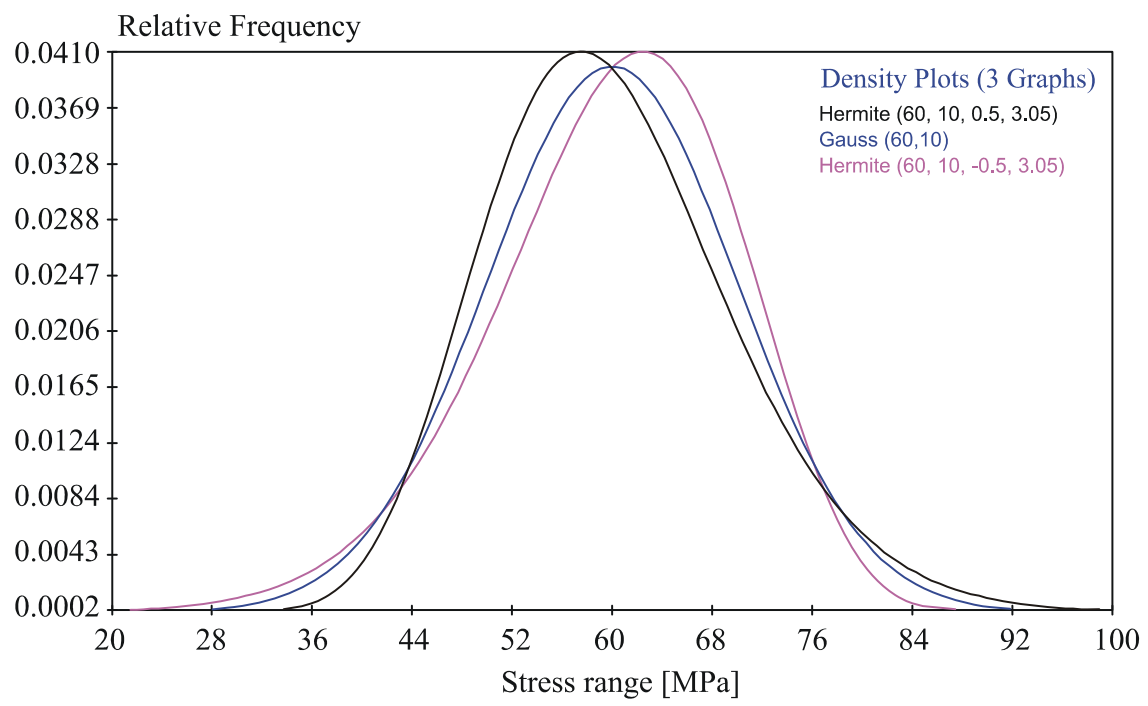

Figure 3. Three variants of stress range random quantities 


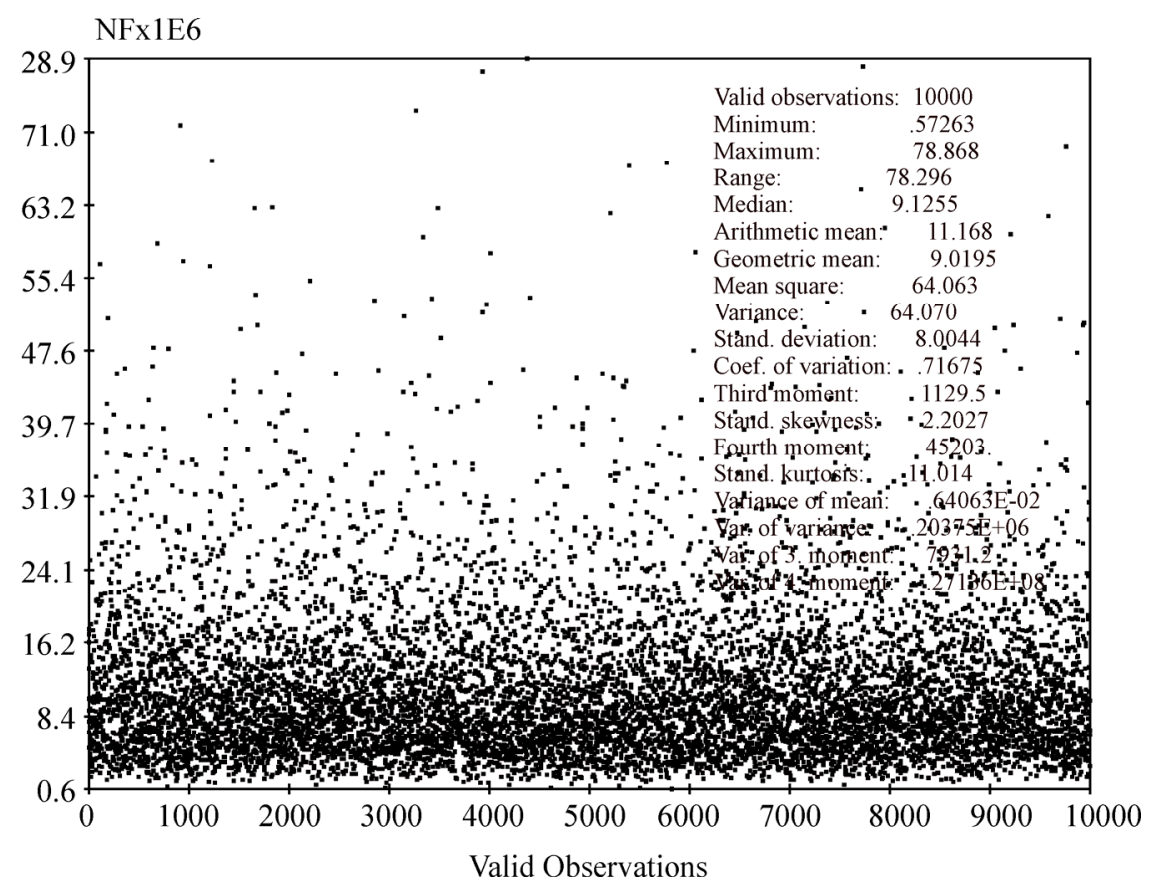

Figure 4. Statistical analysis of $N_{F 1}$ for $\Delta \sigma_{\mathrm{v} 1}$

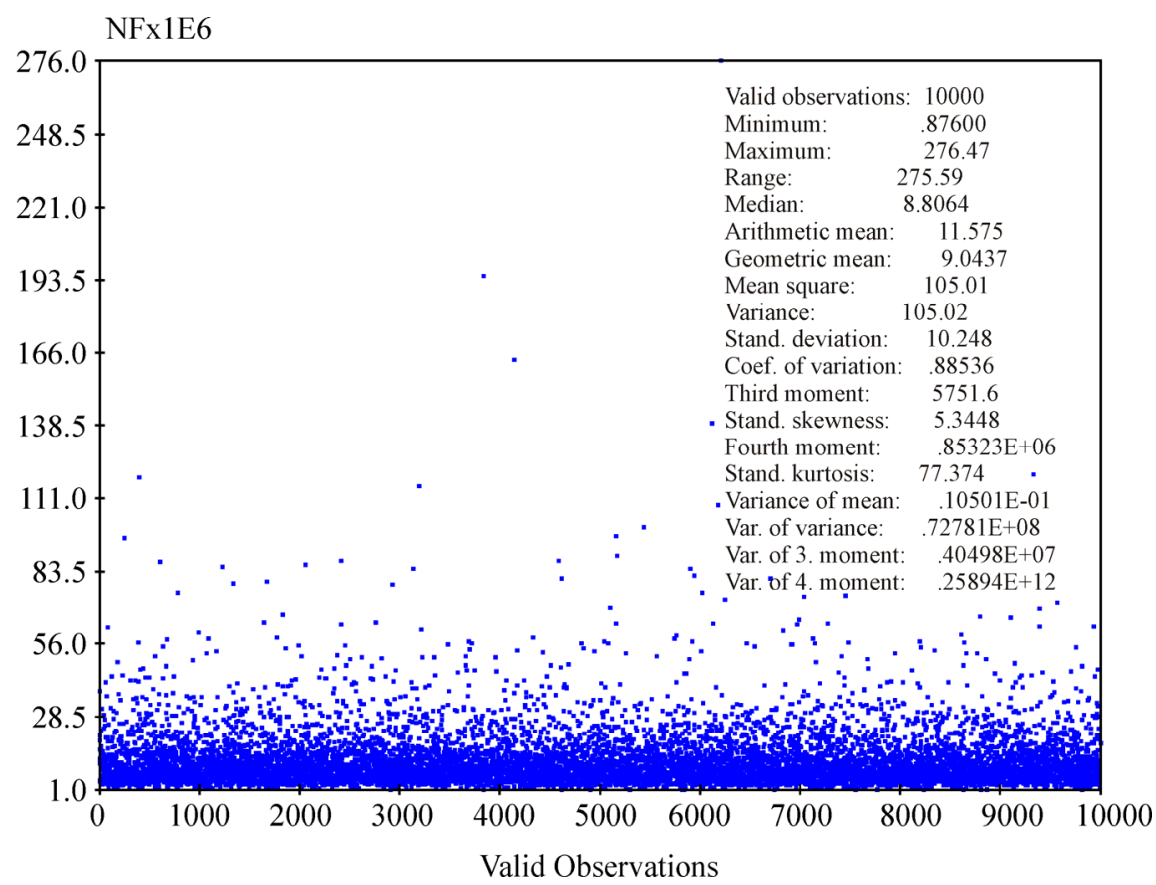

Figure 5. Statistical analysis of $N_{F 2}$ for $\Delta \sigma_{\mathrm{v} 2}$

Results of the statistical analyses are shown in Figure 4, Figure 5 and Figure 6. It is apparent that small changes of skewness have a great influence on the results of the statistical analysis. When the skewness value of $\Delta \sigma$ increases, the mean value, standard deviation and skewness of $N_{F}$ decrease. The effect on kurtosis is opposite, increasing skewness of $\Delta \sigma$ greatly reduces the value of kurtosis of $N_{F}$. The greatest values of skewness and kurtosis are obtained for variant 3 , see Figure 6 . The minimum and maximum values of valid observations are approximately the same for variants 2 and 3, see Figure 5 and Figure 6. On the contrary, variant 1 yields up to ten times lower extreme observation value in comparison to variants 2 and 3. For safe and reliable bridge operation the values of $N_{F}$ should be as high as possible. However, focusing only on the mean values of $N_{F}$ is not sufficient. Although the statistical analysis of $N_{F}$ shown in Figure 6 leads to the highest mean value $N_{F 3}$, the standard deviation of $N_{F 3}$ is higher than those of the other variants. Important conclusions can be drawn only by evaluating the probability that the fatigue resistance $N_{F}$ is higher than the number of fatigue cycles that actually occur on the bridge structure. Knowledge of the actual histogram of $N_{F}$ is very important for evaluating such a probability and procuring accurate information on the input ran- 
dom variables in Table 1 cannot be underestimated. Small inaccuracies in the skewness of $N_{F}$ strongly influence the statistical characteristics and shape of the histogram of $N_{F}$. Therefore, ensuring accuracy of input data is crucial. Similar conclusions can be expected in the case of kurtosis whose influence on $N_{F}$ was not analysed in this paper.

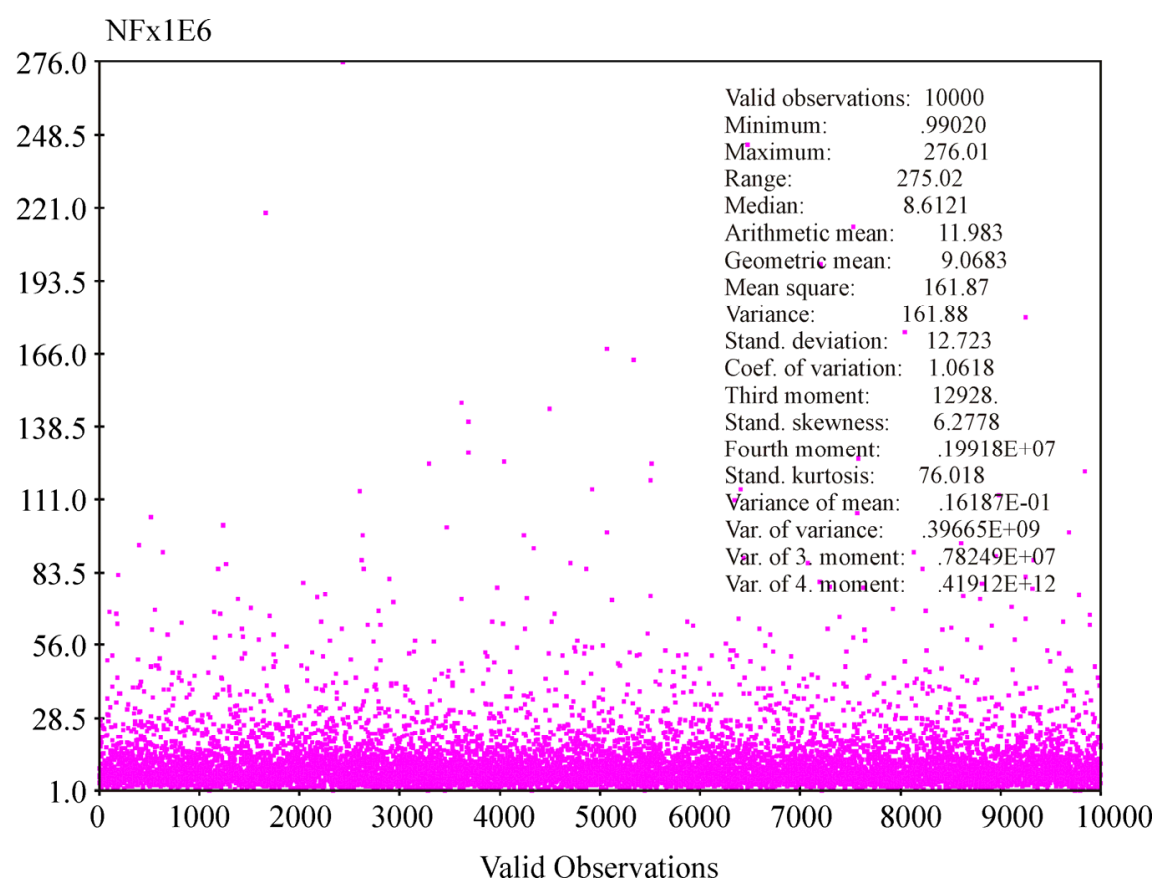

Figure 6. Statistical analysis of $N_{F 3}$ for $\Delta \sigma_{\mathrm{v} 3}$

The sampling of input random quantities was generated for seven statistically independent input variables from Table 1, where five input quantities $a_{0}, a_{c}, W, m, \Delta \sigma$ were used to evaluate runs of $N_{F}$. The same sets of (pseudo-) random numbers are used for input variables $a_{0}, a_{c r}, W, m$ in each variant. Calculating the correlation between $N_{F}$ from the individual variants measures the sensitivity of $N_{F}$ to $\Delta \sigma$, whose (pseudo-) random numbers are different in each variant. Kendall rank correlation coefficients are used for the evaluation of sensitivity analysis, where $\operatorname{corr}\left(N_{F 1}\right.$, $\left.N_{F 2}\right) \approx 0.28, \operatorname{corr}\left(N_{F 1}, N_{F 3}\right) \approx 0.28, \operatorname{corr}\left(N_{F 2}, N_{F 3}\right) \approx 0.28$. The difference between (pseudo-) random numbers in each variant $N_{F i}$ shows that sensitivity of $N_{F 1}$ to $\Delta \sigma$ is approximately thirty percent. The influence of the other variables is lower. Kendall rank correlation coefficients have been proven to be more appropriate sensitivity indicators in this study than Pearson or Spearman rank-correlation coefficients, which corroborates the results in (Omishore, 2018).

Measuring sensitivity based on the effect of changes in (pseudo-) random numbers of the monitored input variable on the correlation between two sets of output variables is a new type of sensitivity analysis, which provides fast response with good results. On the other hand, this type of sensitivity analysis does not allow the identification of the interaction effects between input variables, which would require using global sensitivity analysis based on double-nested-loop simulations (e.g. Kala, 2019a, 2019b).

\section{Conclusions}

Stochastic analysis showed that the fatigue resistance is very sensitive to changes in the skewness of the quasi-constant stress range. The mean value, standard deviation and extreme values of fatigue resistance changed very rapidly with strong implications for the conclusions that could be drawn in connection to the safety and reliability of the bridge member. These results were obtained even though the mean value and standard deviation of the quasi-constant stress range were fixed. The mean value and standard deviation are commonly considered sufficient for the introduction of input random variables because they allow the application of two-parameter probability density functions like Gauss, lognormal, etc. The conclusions of this article are alarming because the first two statistical moments are shown to be generally insufficient for modelling the probability density distributions of input random variables, whose sensitivity to the output is crucial. The identification of such input random variables has to be performed using sensitivity analysis, which is an important part of stochastic modelling. A new type of sensitivity analysis, which identifies the dominant stochastic input variables using changes of (pseudo-) random numbers of input variables and the subsequent measuring of the effect on the correlation between two sets of output variables, was introduced in this paper. The advantage of this type of sensitivity measurement based on non-parametric rank-order correlation is the rapid identification of crucial input variables. However, it is not global sensitivity analysis because higher-order interactions between input random variables are not identified. 


\section{Acknowledgements}

This work was supported by the The Czech Science Foundation (GACR) [grant numbers 17-01589S].

\section{References}

Antucheviciene, J., Kala, Z., Marzouk, M., \& Vaidogas, E. R. (2015). Solving civil engineering problems by means of fuzzy and stochastic MCDM methods: Current state and future research. Mathematical Problems in Engineering, 2015, ID 362579, 1-16. https://doi.org/10.1155/2015/362579

Chalmovský, J., Štefaňák, J., Miča, L., Kala, Z., Skuodis, Š., Norkus, A., \& Žilionienė, D. (2017). Statistical-numerical analysis for pullout tests of ground anchors. Baltic Journal of Road and Bridge Engineering, 12(3), 145-153. https://doi.org/10.3846/bjrbe.2017.17

Cui, W. (2002). A state-of-the-art review on fatigue life prediction methods for metal structures. Journal of Marine Science and Technology, 7(1), 43-56. https://doi.org/10.1007/s007730200012

Ghorabaee, M. K., Amiri, M., Zavadskas, E. K., \& Antucheviciene, J. (2018). A new hybrid fuzzy MCDM approach for evaluation of construction equipment with sustainability considerations. Archives of Civil and Mechanical Engineering, 18(1), 32-49. https://doi.org/10.1016/j.acme.2017.04.011

Guo, T., \& Chen, Y. W. (2013). Fatigue reliability analysis of steel bridge details based on field-monitored data and linear elastic fracture mechanics. Structure and Infrastructure Engineering, 9(5), 496-505. https://doi.org/10.1080/15732479.2011.568508

Iman, R. L., \& Conover, W. J. (1980). Small sample sensitivity analysis techniques for computer models. With an application to risk assessment. Communications in Statistics - Theory and Methods, 9(17), 1749-1842. https://doi.org/10.1080/03610928008827996

Jönsson, J., Müller, M. S., Gamst, C., Valeš, J., \& Kala, Z. (2019). Investigation of European flexural and lateral torsional buckling interaction. Journal of Constructional Steel Research, 156, 105-121. https://doi.org/10.1016/j.jcsr.2019.01.026

Kala, Z. (2008). Fuzzy probability analysis of the fatigue resistance of steel structural members under bending, Journal of Civil Engineering and Management, 14(1), 67-72. https://doi.org/10.3846/1392-3730.2008.14.67-72

Kala, Z. (2012). Geometrically non-linear finite element reliability analysis of steel plane frames with initial imperfections. Journal of Civil Engineering and Management, 18(1), 81-90. https://doi.org/10.3846/13923730.2012.655306

Kala, Z. (2019a). Quantile-oriented global sensitivity analysis of design resistance. Journal of Civil Engineering and Management, 25(4), 297-305. https://doi.org/10.3846/jcem.2019.9627

Kala, Z. (2019b). Global sensitivity analysis of reliability of structural bridge system, Engineering Structures, 194, 36-45. https://doi.org/10.1016/j.engstruct.2019.05.045

Kala, Z., \& Valeš, J. (2018). Imperfection sensitivity analysis of steel columns at ultimate limit state. Archives of Civil and Mechanical Engineering, 18(4), 1207-1218. https://doi.org/10.1016/j.acme.2018.01.009

Kala, Z., \& Valeš, J. (2017). Sensitivity assessment and lateral-torsional buckling design of I-beams using solid finite elements. Journal of Constructional Steel Research, 139, 110-122. https://doi.org/10.1016/j.jcsr.2017.09.014

Kala, Z., Valeš, J., \& Jönsson, J. (2017). Random fields of initial out of straightness leading to column buckling. Journal of Civil Engineering and Management, 23(7), 902-913. https://doi.org/10.3846/13923730.2017.1341957

Krejsa, M., Kala, Z., \& Seitl, S. (2016). Inspection based probabilistic modeling of fatigue crack progression. Procedia Engineering, 142, 146-153. https://doi.org/10.1016/j.proeng.2016.02.025

McKey, M. D., Beckman, R. J., \& Conover, W. J. (1979). A comparison of the three methods of selecting values of input variables in the analysis of output from a computer code. Technometrics, 21(2), 239-245. https://doi.org/10.1080/00401706.1979.10489755

Omishore, A. (2018). Stochastic modelling and prediction of fatigue crack propagation based on experimental research. IOP Conference Series: Materials Science and Engineering, 471, 102037, 1-10. https://doi.org/10.1088/1757-899X/471/10/102037

Paris, P. C., \& Erdogan, F. (1963). A critical analysis of crack propagation laws. Journal of Basic Engineering, 85(4), 528-534. https://doi.org/10.1115/1.3656900

Seitl, S., Miarka, P., \& Kala, Z. (2018). Geometry functions for edge cracks in steel bridge under three- and four- point bending with various span. Transactions of the VSB - Technical University of Ostrava, Civil Engineering Series, 18(2), 1-6. https://doi.org/10.31490/tces-2018-0015

Seitl, S., Miarka, P., Malíková, L., \& Krejsa, M. (2017). Comparison of calibration functions for short edge cracks under selected loads. Key Engineering Materials, 754, 353-356. https://doi.org/10.4028/www.scientific.net/KEM.754.353

Štefaňák, J., Kala, Z., Miča, L., \& Norkus, A. (2018). Global sensitivity analysis for transformation of Hoek-Brown failure criterion for rock mass. Journal of Civil Engineering and Management, 24(5), 390-398. https://doi.org/10.3846/jcem.2018.5194

Ye, X. W., Su, Y. H., \& Han, J. P. (2014). A state-of-the-art review on fatigue life assessment of steel bridges. Mathematical Problems in Engineering, 2014, ID 956473, 1-13. https://doi.org/10.1155/2014/956473

Zerbst, U., Vormwald, M., Pippan, R., Gänser, H.-P., Sarrazin-Baudoux, Ch., \& Madia, M. (2016). About the fatigue crack propagation threshold of metals as a design criterion - A review. Engineering Fracture Mechanics, 153, 190-243. https://doi.org/10.1016/j.engfracmech.2015.12.002 